\title{
Influence of non-equilibrium low-temperature plasma on consumer characteristics of spunmelt material
}

\author{
(C) Maria S. Lisanevich, ${ }^{*+}$ Reseda Yu. Galimzyanova, and Rustem G. Ibragimov \\ Department of Medical Engineering. Kazan National Research Technological University. \\ Karl Marx St., 68. Kazan, 420015. Russia. Phone: +7 (843) 231-43-36. \\ E-mail: lisanevichm@gmail.com
}

Keywords: nonwoven material, spunmelt material, low-temperature plasma, consumer indicators.

\begin{abstract}
Nonwovens (nonwovens) are widely used in medicine, for the manufacture of medical linen, sanitary and hygienic items, medical clothing, surgical materials (including dressings). The rapid development of the clothing market requires domestic manufacturers to be competitive not only through new products and technologies, but also new sensations for the consumer, provided that the price is competitive. According to medical workers, disposable surgical gowns based on spunmelt materials give a feeling of discomfort during use. One and relatively new method for modifying nanomaterials is treatment with nonequilibrium lowtemperature plasma (NLTP). The main advantage of this type of material modification is the environmental friendliness of the method, as in the process of processing aqueous solutions of chemicals are not used, as in the case of using special impregnations. Modern research of medical services. As a result of the work, it was revealed that the modification of NM NNTP allows you to change the NM for changes in surface, physical and mechanical, as well as consumer properties, while maintaining the strength characteristics. It is shown that after plasma treatment spunmelt materials increase such consumer characteristics as air permeability, hygroscopicity, while maintaining the strength during elongation; reduction of material stiffness during bending. It was also found that after the processing of NTPP, the electrification rate increases within the normal range, in GOST 12.1.045-84. Manufacturers are recommended to process spunmelt material with nonequilibrium low-temperature plasma on a high-frequency capacitive plasma installation with a power of $\mathrm{Wp}=$ $1.5 \mathrm{~kW}$, processing time $\tau=180 \mathrm{~s}$ and pressure $\mathrm{P}=21.5 \mathrm{~Pa}$. Use argon gas with a gas flow of $1500 \mathrm{~cm}^{3} / \mathrm{min}$ as a plasma-forming gas.
\end{abstract}

\section{References}

[1] Yu.N. Khakimullin, A.R. Bakhridinova, R.R. Shaimardanova, M.S. Lisanevich, R.Yu. Galimzyanova. The effect of radiation sterilization on the properties of spunmelt materials. Bulletin of Technological University. 2015. Vol.18. No.1. P.251-253. (russian)

[2] Yu.N. Khakimullin, M.S. Lisanevich, R.Yu. Galimzyanova, B.L. Shakirov. Prediction of the durability of a laminated nonwoven material sterilized by ionizing radiation. Bulletin of the Technological University. 2015. Vol.18. No.17. P.120-122. (russian)

[3] Yu.N. Khakimullin, E.R. Rakhmatullina, R.Yu. Galimzyanova, M.S. Lisanevich, I.E. Kogenman, R.S. Yarullin. The possibility of obtaining nonwovens resistant to traditional methods of sterilization in the conditions of modern production. Bulletin of Kazan Technological University. 2013. Vol.16. No.23. P.118-120. (russian)

[4] M.S. Lisanevich, K.V. Legaeva, E.E. Tsareva, R.Yu. Galimzyanova, I.N. Musin, Yu.N. Khakimullin. Predicting the durability of sterilized nonwoven fabrics produced using spunlace technology. Bulletin of Kazan Technological University. 2014. Vol.17. No.14. P.144-146. (russian)

[5] R.Yu. Galimzyanova, B.L. Shakirov, I.E. Kogenman, L.S. Travkina, M.S. Lisanevich, Yu.N. Khakimullin. Influence of radiation sterilization on the properties of two-layer laminated nonwoven fabric. Bulletin of Kazan Technological University. 2014. Vol.17. No.14. P.194-196. (russian)

[6] Yu.N. Khakimullin, K.V. Legaeva, E.S. Kuznetsova, L.S. Travkina, M.S. Lisanevich, R.Yu. Galimzyanova. Influence of radiation sterilization on the properties of nonwoven fabric obtained by spunlace technology. Bulletin of Kazan Technological University. 2014. Vol.17. No.14. P.150-153. (russian) 
[7] R.Yu. Galimzyanova, Yu.D. Shakirova, M.S. Lisanevich, Yu.N. Khakimullin, A.P. Zhanzhora. Influence of gamma and electron radiation during radiation sterilization on the properties of a material based on viscose fiber. Bulletin of Technological University. 2016. Vol.19. No.10. P.99-101. (russian)

[8] A.E. Tsarev, M.S. Lisanevich. Investigation of the effect of radiation sterilization on the electrostaticity of nonwoven spunmelt materials for medical use. In the collection: Fundamental and applied problems of creating materials and aspects of technologies for the textile and light industry. Collection of articles All-Russian scientific and technical conference. under. ed. L.N. Abutalipova. 2019. P.47-50. (russian)

[9] R.Yu. Galimzyanova, E.R. Rakhmatullina, M.S. Lisanevich, Yu.N. Khakimullin. Influence of radiation sterilization on the physical and mechanical properties of polypropylene-based nonwoven fabric. Bulletin of Technological University. 2020. Vol.23. No.2. P.19-23. (russian)

[10] Yu.N. Khakimullin, G.M. Gilmutdinova, A.R. Bakhridinova, M.S. Lisanevich, E. Rakhmatullina, R.Yu. Galimzyanova. Investigation of the influence of non-equilibrium low-temperature plasma on the properties of laminated nonwoven fabric. Izvestiya of Higher Educational Institutions. Light Industry Technology. 2016. Vol.34. No.4. P.68-71. (russian)

[11] R.Yu. Galimzyanova, M.S. Lisanevich, Yu.N. Khakimullin, N.S. Podemirova, K.V. Legaeva. Influence of non-equilibrium low-temperature plasma on the properties of nonwoven multilayer material based on polypropylene. Bulletin of Technological University. 2015. Vol.18. No.16. P.141-143. (russian) 